$18^{\text {th }}$ Conference of the Egyptian Society of Animal Production, Hurghada, Egypt, November 7 - 10, 2018

\title{
MANDARAH MALE CHICKS PRODUCTIVE PERFORMANCE AND ORGANS WEIGHT AS AFFECTED BY USING VARIOUS ROUTES OF SYNBIOTICS TREATMENTS
}

\section{M. Youssef ${ }^{1}$, A.M. ${ }^{2}$ Abdel-Ghany, E.G. Ahmed ${ }^{2}$ and S.M. Mahmoud ${ }^{1}$ \\ 1- Department of Poultry Breeding, Animal Production Research Institute, Agriculture Research Center, Egypt, 2- Department of Animal Production and Fisheries, College of Agriculture, Suez Canal University, Egypt}

Current study was conducted to investigate the effects of using various routes of Synbiotics administrations on productive performance and organs weights of developed Mandarah Male chicks. A Two hundred and ten one-days old male chicks of the indigenous Mandarah strain were assigned randomly into seven treatments (three replicates/treatment each of 10 chicks; 30 chicks/treatment). All groups were kept under the same conditions as regard to managerial; feeding a grower diet containing $19.23 \%$ crude protein, $2850 \mathrm{Kcal} / \mathrm{kg}$ Metabolize energy (ME) and 3.20\% crude fiber and veterinary-health- and vaccination-program-procedures. Feed and water were offered ad libitum.

Route and dosage of the one-time Synbiotics' treatments to One-day old chicks were as follow: 1- Basal diet chicks with no treatment (control; G1-no treatment);

2- Spraying with $0.25 \mathrm{ml}$ Synbiotics (containing 5 X $10^{7}$ CFU-G2-single dose);

3- Spraying With $0.50 \mathrm{ml}$ Synbiotics (containing $5 \times 10^{8}$ CFU-G3-double dose);

4- Drinking water with $0.25 \mathrm{ml}$ Synbiotics (containing 5 X $10^{7}$ CFU-G4-single dose);

5- Drinking water with $0.50 \mathrm{ml}$ Synbiotics (containing $5 \times 10^{8}$ CFU-G5-double dose);

6- Mouth drops with $0.25 \mathrm{ml}$ Synbiotics (containing 5 X $10^{7}$ CFU-G6-single dose) and 7- Mouth drops with $0.50 \mathrm{ml}$ Synbiotics (containing $5 \times 10^{8}$ CFU-G7-double dose).

At $16^{\text {th }}$ week of age three birds from each treatment (this gives rise to a total of 21 birds) were slaughtered to determine carcass characteristics and relative weight ( $g$ ) of lymphoid organs. Results indicated that body weight, feed intake and feed conversion ratio were significantly improved $(\mathrm{P} \leq 0.01)$ and highest/best values when using Synbiotics in drinking water $(\mathrm{G} 4$-single dose) compared with the control and other treated groups. However, carcass and Lymphoid organs (g) were not affected by treatments $(\mathrm{P} \geq 0.05)$. Nevertheless, the chickens administered by $0.25 \mathrm{ml}$ Synbiotics via mouth/oral drops (G6) showed a significant increase $(\mathrm{P} \leq 0.05)$ in spleen weight than that of the control (G1-no treatment) and other treated groups. 